\title{
Del uso PÚBLICO dE LA RAZÓN: RACIONALIDAD REFLEXIVA Y ESPACIO PÚBLICO
}

\author{
Alejandro Sahui Maldonado \\ Professor da Universidad Autônoma de Campeche, México. \\ E-mail: alesahui@hotmail.com
}

\section{Resumen}

El artículo es un esfuerzo de reflexión en el sentido de demostrar que en un discurso consistente sobre la democracia y sobre los derechos humanos hay que tener en cuenta la existencia de espacios públicos que garanticen la pluralidad de posiciones y actores. Pero ese público no significa, solamente, espacio de conflictos que abarca todos los comprometidos y les asegura el habla, tampoco significa una comunidad harmónicamente basada en la tradición o la religión, sino un espacio volcado hacia la construcción de un mundo común y, bajo esta perspectiva, un espacio a partir del cual, de forma ética y, evidentemente, sin constreñimientos, se pueda acoger y legitimar las más distintas posiciones.

Palabras clave: espacio público; participación política; ciudadanía.

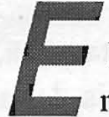

propósito del presente trabajo acerca de lo público y su racionalidad surge de una personal preocupación por comprender las formas y modos en que las personas nos entendemos y por cómo nos procuramos respeto los unos a los otros como libres, iguales y, quizás, mucho más especialmente, como diferentes y únicos. La intención es demostrar que sólo a través de formas incluyentes de discusión pública es posible articular un discurso consistente de la democracia y los derechos humanos. No se pretende, sin embargo, ofrecer una descripción de la realidad o la historia de los espacios públicos, sino más bien sugerir un modelo que pueda servir como marco de reflexión acerca de cómo podríamos hoy pensar y comprender lo público en sociedades -más o menos- democráticas. 
La labor de investigación se perfila como un ejercicio de crítica contra una forma de reflexión que suele identificar un tipo histórico concreto de instituciones y prácticas con el modelo puro y único que realizaría los principios y valores de la publicidad tal y como se los entiende en las sociedades "desarrolladas". Cualquier otro sería denunciado como desviado o imperfecto. Los muy diversos cursos históricos de cada país y cultura son en este modo constreñidos a ajustarse a pautas de evolución u organización inviables. Estoy convencido de que con idénticos principios a los que han dado origen a las sociedades que solemos nombrar del "primer mundo" -en este caso, el principio de publicidad- sería posible pensar, crear o comprender formas distintas de organización no autoritarias. Aclaro que no me refiero a inventar nuevas prácticas de la nada, sino a buscar e identificar "en cada caso" los medios idóneos para que aquellos principios puedan realizarse en las distintas situaciones particulares. Tampoco quiero decir que los principios deban acomodarse a cada una de las prácticas e instituciones existentes en esas otras sociedades, y que de no ser posible tenga que desechárselos ; conocemos y valoramos positivamente sus efectos necesariamente perturbadores o disruptivos (en términos de Luis Villoro). Por tanto, el problema no es nunca con dichos principios sino más bien con algunas formas que aquéllos han encarnado -de manera contingente- y que pretenden muchas veces confundirse con ellos. Así, aquí se procuraría deslindar claramente los principios en sí mismos de cualquier aditamento superfluo.

Consideramos que -frente al tema que nos ocupa en esta mesa, el de "los espacios de la democracia"- privilegiar el análisis de la publicidad a través de nuestras formas de discusión, es decir, de los modos en que ejercemos nuestra racionalidad cuando dialogamos con nuestros semejantes presenta considerables ventajas respecto a concentrarse en el análisis de otros conceptos, tales como Estado, Mercado o Sociedad Civil. Las dificultades, por poner un ejemplo, de esta última noción tan frecuente como confusamente utilizada se ponen de manifiesto cuando se intenta identificar su referente en el plano de los hechos, es decir, cuando frente a determinadas circunstancias se observa un permanente y continuo cambio de los actores que en las distintas épocas se nombran como integrantes de esa sociedad civil, y 
cuando nos percatamos de los inevitables cruces y solapamientos precisamente entre sus agentes, el Estado y el Mercado, implicados siempre en su concepto ; lo cual lo hace muy poco operativo en términos teóricos. Y es que el crecimiento de la administración pública con el Estado social de bienestar, por un lado, y los complejos procesos de globalización económica, por el otro, han contribuido a hacer cada vez más difusos los límites : ¿es un funcionario del Estado miembro de pleno derecho de la sociedad civil ? ¿lo es un agente de la bolsa de valores ? ¿lo son ambos acaso sólo en determinados horarios -su tiempo libre- y únicamente respecto de unos pocos temas ? Cohen y Arato han dado cuenta ya de algunas de estas dificultades en relación con el concepto de sociedad civil. Nuestra sospecha es que se precisa de un modelo de reflexión que no prejuzgue acerca de quién o quiénes, qué momentos, qué lugares, ni mucho menos qué temas de discusión, sean considerados elementos sustantivos -necesarios, suficientes y excluyentes- de los espacios democráticos. Pensamos entonces en la democracia como una forma de organizar la vida en sociedad, necesariamente dependiente de contextos de publicidad libre. De ello trataremos en lo que sigue.

No adelantamos ninguna definición sustancial acerca de qué sea exactamente el ámbito público, ni de su distinción respecto de los ámbitos privado, social o íntimo. Sus fronteras no han sido nunca-ni lo son hoy-suficientemente claras como para poder darse una respuesta satisfactoria; lo que es más, no es sólo que dichas fronteras sean borrosas, sino que también son variables y relativas, lo que se hace evidente si observamos su devenir histórico. En el esfuerzo por acotar el espectro de lo público una de nuestras mayores prevenciones ha sido evitar cualquier exclusión no justificada de personas, razones o temas. Estas prevenciones se sostienen en la percepción de que normalmente dichas exclusiones se han "justificado" desde argumentaciones metafísicas o religiosas acerca del mundo y de su orden que se conciben como necesarias e inescrutables. La quiebra y fracaso de estas explicaciones hoy debido a sociedades crecientemente plurales y complejas, al acercamiento intercultural de un mundo mucho más pequeño como consecuencia de los cada día mejores medios de comunicación globales, así como a una secularización casi generaliza- 
da de las visiones del mundo en los diferentes pueblos, o, al menos, de las formas de concebir su organización política, previene de un modo de proceder semejante. Es decir, la circunstancia señalada de que no existe una limitación "a priori" fijada de una vez y para siempre acerca de la clase de contenidos únicos susceptibles de ser tratados en el ámbito público, y de que tampoco existen lugares físicos concretos donde éste se manifestaría de manera natural y excluyente, sino que sus fronteras han sido históricamente variables, nos obliga a un esfuerzo serio de búsqueda de formas por todos aceptables para entendernos y organizar nuestras vidas en sociedad. En este esfuerzo por pensar lo público de manera tal que se de cuenta de su variabilidad histórica y de su no-esencialidad, hemos intentado recuperar la intuición que está detrás de la noción kantiana del "uso público de la razón" situada en sus escritos de filosofía política y de la historia porque estimamos que ella anticipa una idea de la publicidad no atada a condiciones empíricas -espaciales o temporales-, sino que más bien sugiere una noción relacional y reflexiva constituida fundamentalmente a través de un particular modo de ejercer la razón frente a los demás y vinculada necesariamente a la idea de autonomía y libertad. La idea es entonces que cuando las personas deliberamos acerca de las condiciones de la libertad es cuando lo público se constituye y adquiere su mayor relevancia en el plano normativo ; su ausencia, en cambio, se manifiesta cuando la libertad es violentada y la participación sistemáticamente negada. Nuestra idea es que lo público es, antes que un lugar o una cierta clase de temas, más bien un modo de proceder en nuestras discusiones. Es de fundamental importancia la "guía de lectura" de Kant brindada por Habermas y Rawls, ya que hace posible destrascendentalizar el sistema kantiano y la recuperación para los propios sujetos concretos -con necesidades, intereses y deseos- la capacidad de constituirse en la fuente validadora de sus derechos y de los acuerdos posibles acerca de su autocomprensión ético-política. No hacen falta ya más "razones prácticas" impracticables que se conciben muy por encima de los individuos reales o "lechos de Procusto" diseñados en apretadas tallas pensadas para bellísimas pero inalcanzables modelos. Tal vez sea la sencillez con que se presenta una concepción de un orden sólo inteligible del mundo la que oculta su 
impracticidad en un mundo que en realidad solemos percibir como complejo. Pues bien, el tipo de racionalidad público-política que intentamos proponer no tiende en modo alguno a allanarnos o facilitarnos el camino en el sentido de descargar de cada uno de nosotros la responsabilidad de decidir en todo momento "quiénes y cómo somos, y cómo queremos y debemos ser".

Tanto Habermas como Rawls acuden al imperativo kantiano del "reino de los fines" por el que cada individuo es un autolegislador universal que "debe tratarse a sí mismo y tratar a lo demás, nunca como simple medio, sino siempre al mismo tiempo como un fin en sí mismo". La reconstrucción de dicho imperativo en términos intersubjetivos a través de "la pragmática formal del lenguaje, o de las constricciones razonables al diseño de la posición original”, respectivamente, hacen posible este importante cambio en la filosofía kantiana, abandonándose su concepción de la razón de carácter estrictamente monológico o individual. En Habermas, además, hay un camino paralelo al de la pragmática del lenguaje que tiene que ver con la máxima kantiana del "pensar extenso o ampliado", del "ponerse en el lugar del otro" y reconocer y asumir sus diferentes roles y perspectivas.

Y es que sólo el paso de una concepción monológica de la racionalidad a una concepción intersubjetiva o dialógica nos permite proponer un tipo de publicidad semejante. Este concepto interesado de publicidad -hay que precisarlo- es un concepto antes que nada "normativo", un ideal que se ofrece a un tiempo como "constitutivo y como regulativo". Debe, empero, ser también un ideal realizable a la luz no decimos ya de los hechos históricos brutos, sino de las experiencias comunes acerca de ellos que a diario contribuyen a modelar nuestra autocomprensión como sujetos situados. Hemos señalado que la naturaleza dialógica de la racionalidad permite pensar lo público de una manera peculiar y deseable. Podemos decir incluso que en nuestras concepciones de la racionalidad política las nociones de intersubjetividad y de publicidad en ocasiones se solapan, aunque no siempre son coextensas. De estas dos nociones la idea de intersubjetividad parece primigenia en cuanto se presenta como una "aptitud epistémica", como un especial modo de concebir la racionalidad, antes anclada en una noción monológica del conocimiento 
y la razón. En este plano la intersubjetividad puede ser asimilada en gran medida a lo público en su sentido de ideal "constitutivo", o sea, como las condiciones de posibilidad de un especial modo de ejercer nuestra razón adecuado a un mundo que se halla estructurado simbólicamente y que por ello precisa de interpretaciones comunes ; interpretaciones éstas que sólo podemos procurarnos por medio del diálogo entre todos los sujetos susceptibles de ser afectados por las decisiones tomadas. Del otro lado, sin embargo, no menos importante, la publicidad como idea "regulativa" puede entenderse en una acepción más directamente práctica que se orienta hacia nuestra disposición a escuchar y considerar con seriedad todos y cada uno de los puntos de vista de aquellos posibles afectados por nuestras decisiones, al extremo de estar abiertos a la eventual mudanza de la propia perspectiva. En este segundo sentido la publicidad "revierte" sobre su ideal constitutivo siempre que las creencias que compartimos del mundo -"en las que estamos y nos movemos"- se quiebran, sea por el cambio de las circunstancias en que surgieron, por la percepción de fenómenos de los que antes no éramos conscientes, o bien, por el encuentro con formas diferentes de ver el mundo que nos cuestionan fuertemente. Aquí el ideal nos urge a revisar en común, "juntos", si las premisas que entonces afirmábamos como las mismas condiciones de la intersubjetividad, a saber : la reciprocidad y simetría, la generalidad y la universalidad, eran en realidad tales, o en cambio, dependían de definiciones estrechas y parciales. Para Kant el ideal regulativo de la publicidad es también importante en el ámbito constitutivo de la racionalidad como dialógica porque sólo su continuado y libre ejercicio con nuestros semejantes permite que subsista la razón individual.

Por estos motivos el espacio de lo público para nosotros no significa la mera concurrencia o presencia simultánea de los actores en escenarios determinados, llámense éstos ágoras o recintos parlamentarios, ni tampoco la simple secuencia reglamentada de las distintas voces donde no hay un diálogo verdadero orientado al entendimiento sino solamente interminables y estériles monólogos, en que nadie escucha a nadie, pero eso sí, todos esperan ansiosos su turno para hablar. Pero público tampoco es sinónimo de "comunidad" ẹn el sentido de una clase especial de asociación unida por una doctrina 
comprehensiva, una tradición, o una cosmovisión religiosa, aunque tampoco niega la posibilidad-amplia- de que sus ámbitos coincidan en el plano fenoménico. Es más, creo que podemos sostener que lo público sí se dirige a la constitución de un mundo social común, de una "común unidad"; sin embargo ésta presentaría importantes rasgos distintivos de aquella otra configurada "desde antes y por detrás" de las conciencias de los sujetos. La singularidad de esta "comunidad" de lo público consiste básicamente en la siempre presente "común disponibilidad" de las razones y motivos que justifican todas y cada una de las normas que determinan sus cursos de acción y las maneras de autocomprenderse ética y políticamente, pero también como una "comunidad moral" o "cosmopolita"; es decir, consiste en la posibilidad suficiente de "hacer explícitos" a partir de las creencias compartidas ya más o menos firmes los resortes de una subjetividad compleja que nos arroja a un mundo -aquí sí, entendido como "lugar" - en el que no estamos solos, sino en donde nuestras acciones tienen siempre consecuencias, a veces irreversibles, sobre los demás. Dar y pedir razones, hacerse comprender por los demás y comprenderlos a su vez es el imperativo básico que nos demanda el principio de la publicidad. Por otra parte, dicho principio nos requiere también un uso no estratégico de nuestra razón, es decir, nos reclama sinceridad y honestidad, claridad y transparencia en la exposición de los argumentos que presentamos, $y$, especialmente, coherencia como no hacer excepciones con nosotros mismos. Parece ser, no obstante, que en este respecto el ideal de la publicidad cuida en gran medida de sí mismo en tanto que la exposición continuada de nuestras razones particulares, a la luz de nuestras acciones, dificulta sostener cualquier posible engaño por mucho tiempo. Y aquí hemos vuelto a los escritos de filosofía política y de la historia de Kant en los que el principio de publicidad contiene un potencial inmenso e indefectible de Ilustración en un sentido de "liberación o emancipación", o sea, de la posibilidad de servirnos de la propia razón sin la guía de nadie más, o bien, respecto de nuestras tradiciones y prejuicios.

Con el apoyo de esta noción de uso público de la razón, pensada intersubjetivamente, creemos que puede dejarse provisionalmente de lado la concepción de lo público o de la sociedad civil desarrollada 
desde la construcción de la esfera burguesa, mucho más ligada a una muy particular evolución histórica, y entendida usualmente como su correlato formal -rayana peligrosamente a veces en una platónica idealización-. En cada época, lugar y circunstancia los sujetos han decidido qué poner a resguardo de la mirada del público según el modo en que comprenden el espacio de su subjetividad. Así, las esferas de intimidad, privacidad o publicidad, los ámbitos estatales o del mercado, no forman parte de un orden inamovible y necesario del mundo en función de sus distintas materias, sino que constituyen ámbitos diferenciados sólo histórica y contingentemente como resultado de la voluntad unida de los propios individuos. Seyla Benhabib ha llamado "procedimental" a este modelo de publicidad debido a que en él no importa el contenido o materias de las discusiones políticas ni el lugar físico en que hacen su aparición, sino más bien ha de tenerse únicamente en cuenta que el discurso se desarrolle libre de constricciones, porque no hay manera de predefinir el carácter de los temas antes de cualquier deliberación : "la distinción entre la justicia y la vida buena, normas y valores, intereses y necesidades, es interna y no externa al proceso de formación discursiva de nuestra voluntad". Así, las distinciones entre lo público y lo privado deben poder ser siempre reconceptualizadas. Creo que no hay otra forma de concebir un ámbito verdaderamente democrático que no sea aquél en que existan las condiciones lo suficientemente libres para que los mismos sujetos sean quienes se hagan cargo de todas y cada una de las formas de su organización y de las definiciones que a ellos atañen.

Este tema de la indeterminación "a priori" de las esferas privada o pública, pero también de las esferas íntima o social, es sumamente importante debido a que atañe directamente a los espacios de libertad de los individuos, a sus autonomías. En Habermas, los presupuestos de la praxis argumentativa como condiciones posibilitadoras de "cualquier" argumentación, al incluir el rasgo mismo de la publicidad en el sentido de una exposición abierta y asequible a todos los participantes en un discurso práctico, permiten examinar y cambiar en todo tiempo los límites establecidos. Por ello, estamos siempre autorizados a introducir cualquier temática en el seno de nuestros debates. Podemos hablar públicamente, por ejemplo : de normas y de principios ideales o 
universales, pero también de valores concretos o contextuales; del sentido correcto de la justicia, pero también de las distintas maneras de comprender una vida como buena o realizada -ya sea como individuos o como comunidades-; de lo que consideramos íntimo y debe por tanto ser puesto a resguardo de los demás, y de lo que por el contrario creemos relevante de ser públicamente expuesto ; de cuestiones científicas o técnicas, de racionalidades de medios y fines, como las de los programas económicos y los planes de gobierno; podemos incluso negociar estratégicamente. Lo interesante es que el elemento de la publicidad como presupuesto pragmático del discurso contribuye a situar -o resituar- cada uno de estos contenidos, con sus lógicas, en los necesarios ámbitos diferenciados de nuestras vidas. Por su parte, John Rawls ha señalado que un dominio o esfera de la vida no es algo "ya dado" aparte de una concepción pública de la justicia, ni tampoco un tipo de espacio físico o lugar, sino más bien el resultado de aplicar los principios de la justicia sobre la estructura básica de la sociedad y sobre sus diversas asociaciones. El diseño por el teórico de dicha concepción de la justicia, el trazado de lo que la estructura básica es y de lo que excluye, depende de su capacidad de articular en su derredor un consenso entrecruzado suficiente de los propios ciudadanos. Es decir, son ellos mismos quienes tienen la última palabra acerca de qué es susceptible de tratamiento público.

Un espacio público semejante con estructuras de racionalidad suficientemente reflexivas debe estar integrado por individuos que dispongan de una conciencia moral de un nivel postconvencional, en el sentido de Lawrence Kohlberg ; etapa que supone la existencia de unos principios éticos universales. Dicho de esta forma cabría pensarse en forma apresurada que al referirnos directamente a los individuos significamos un espacio constituido de manera "atomista", como si éste pudiera descomponerse para su comprensión en términos analíticos y aún temporales comenzando desde sujetos aislados que anticiparían órdenes más o menos complejos según sus disposiciones cognitivas y prácticomorales. No es esto lo que queremos decir. Por ello hemos insistido tanto en las características de "intersubjetividad y publicidad" antes de arribar a este punto. Estimamos que las estructuras de la racionalidad pública y nuestras subjetividades se coimplican, pues éstas se forman en un "mun- 
do común público", en espacios socializados que, sin embargo, no se nos imponen indefectiblemente, sino que contribuimos a la vez a modelar ; digamos que de manera "reversible".

Un ejercicio de abstracción como el que aquí estamos intentando, empero, no implica en forma alguna negar el contexto de surgimiento de la idea de publicidad, sino solamente procurarle una mayor capacidad de dar cuenta de las nuevas y siempre cambiantes formas de las relaciones humanas ; es decir, dotarlo de una suficiente reflexividad para poder volverse sobre sí mismo y revisar "caso por caso" los modos concretos e históricos en que se fue configurando, es decir sus contextos de aplicación y justificación. Pero para ello se requiere precisamente la "participación real, libre e igual de todos los sujetos" en cualquier toma de decisiones colectivas que les afecten, ya que si lo público se refiere básicamente a un modo especial de ejercer nuestra racionalidad, de expresar nuestras ideas y de dialogar con nuestros semejantes, lo que parece entonces es que nos encontramos frente a un espacio potencial e ilimitadamente abierto a cualquier persona capaz de hacer tal uso de su razón. En este sentido, al recuperarse para los propios sujetos "en todo momento y a través del diálogo" la capacidad de determinar y definir el espacio de publicidad, y con él, también los ámbitos de privacidad e intimidad, se da cuenta de la inexistencia de un orden absoluto y ahistórico del mundo y del lugar que ocupan los sujetos en él : -insistimos- cualquier asunto puede devenir público cuando los agentes deciden que debe ser discutido. Los riesgos, ciertos sin duda, de esta concepción derivados de la posibilidad siempre presente de revisar, e incluso de devolverse sobre algunos de los logros realizados, de romper cualquier "coto vedado" de derechos, son más bien mínimos cuando aquella concepción de lo público se observa como un voto de confianza a ciudadanos responsables, participativos y reflexivos, y se detecta que enfrente de ella pueden incoarse concepciones poco democráticas de la publicidad política. Piénsese, por ejemplo, cómo las distintas generaciones de derechos han obligado a redefinir y ampliar sus propios límites. Lo anterior significa mantener para los espacios públicos una racionalidad situada y vigilante que, de manera "reflexiva", obligue al mismo tiempo a los sujetos a trascender determinados contextos poniendo a salvo aquella mirada crítica que permita tomar 
distancia de nuestras tradiciones y prácticas cotidianas ante una posible constricción no justificada de nuestra libertad, así como para pensar estados de cosas alternativos. De ahí la importancia de una constante y permanente revisión y tematización de las formas de organizar nuestras relaciones interpersonales. Se busca también con este tipo de racionalidad impedir la adopción de una postura complaciente acerca de los logros alcanzados. Porque no hay estructuras formales que puedan descargarnos de una vez y para siempre de la responsabilidad de decidir en cada caso particular, tenemos que atrevernos a pensar juntos "sin barandillas" que nos prevengan del permanente riesgo de caer. En una sociedad secular y madura, en palabras de Mead, los errores no son pecados.

Ahora bien, el tema de las definiciones sustantivas en circunstancias concretas acerca de los rasgos identitarios de la publicidad, por ejemplo, de lo que en cada época es igualmente relevante para el respeto de las personas, los necesarios límites de las libertades para la convivencia y la acentuación de su carácter negativo o positivo, lo que debemos entender por buenos o razonables argumentos en cada caso, lo susceptible de tematización en un momento dado, etc., es algo que tiene que ver desde siempre con ese constante pero accidentado proceso de aprendizaje moral colectivo que es la historia humana. Desde luego, entonces, que no son irrelevantes las definiciones normativas o ideales de la publicidad que en cada momento utilizamos como raseros de legitimidad o validez de las decisiones políticas y que desde nuestra comprensión como ciudadanos de sociedades más o menos democráticas entendemos sólo son aceptables como decisiones "de todos y cada uno de los en ellas implicados"; pero tampoco son estas mismas definiciones definitivas e inamovibles. Sin embargo, lo traumático de las experiencias de redefinición sí que depende de la "capacidad de aprendizaje y adaptación" que el modelo adoptado posea frente a las complejas y cambiantes formas de la interacción humana. Debido a ello debe buscarse, antes que cualquier otra cosa, un modelo normativo de la publicidad con estas aptitudes cognitivas. Aptitudes éstas que, a final de cuentas, deben poder ser siempre reconducidas a las capacidades de que disponen los propios sujetos, que en sus deliberaciones lo conforman. Esta irrestricta apertura de la racionalidad política a las continuas redefiniciones entre las distintas esferas de la vida es asegurada por el 
ideal regulativo de una publicidad que nos insta en forma permanente a escuchar y atender todas y cada una de las diversas perspectivas e interpretaciones acerca de qué aspectos deben ser considerados relevantes a la hora de definir algo como un interés generalizable y/o universalizable, y que incluso, aún no siéndolo, sus titulares continúen siendo estimados dignos de respeto.

Al subrayar estos rasgos del espacio público hemos estado insistiendo en la "flexibilidad" del modelo, flexibilidad que aquí entendemos en lo esencial como la capacidad y la disposición de dicho espacio al aprendizaje continuado y permanente. Decimos normalmente que "aprendemos" cuando adquirimos algún conocimiento o creencia - "saber o creer qué" - o habilidad - "saber cómo", de que antes no disponíamos. En este uso, aprender se entiende como una facultad eminentemente cognoscitiva que atañe en forma directa a las estructuras de nuestra subjetividad y al especial modo en que éstas se modifican. En cualquier caso, sin embargo, difícilmente predicamos de alguien un aprendizaje si antes no hemos observado en él una manera de actuar y comportarse que revele al menos ostensivamente una "disposición" nueva respecto de su conducta, o bien, si no es capaz de "hacer explícito" aquel "recién estrenado" saber del que hace gala. Así, en el curso diario de nuestras vidas efectuamos complicadas operaciones lógicas y matemáticas, recitamos poemas, conducimos el auto, nos atamos los cordones de los zapatos, como hablamos y caminamos, e invariablemente, de todos estos "saberes" solemos decir que los hemos aprendido, aunque no siempre seamos capaces de "explicitar cuándo y cómo" lo hicimos. Esto es así porque muchos -si no es que la mayoría- de nuestros saberes los hemos adquirido sin ser plenamente conscientes de ello. Algunos, como por ejemplo hablar o caminar, los efectuamos sólo mecánicamente, mientras que quizás existan otros que sólo puedan nombrarse tales cuando podemos representárnoslos, así como comunicarlos suficientemente ; en pocas palabras : que podamos tener una relación reflexiva con ellos. Lo que aquí sostenemos es que nuestros procesos de aprendizaje y saberes en los ámbitos "público-político y moral" sólo son plausibles a largo plazo cuando discurren al nivel de la conciencia explícita de los propios sujetos y/o de sus instituciones; conciencia e instituciones éstas que en nuestro caso se 
constituyen únicamente a través de estructuras de intersubjetividad y publicidad. Ser capaces de explicitar estos saberes, "argumentar y dar razones" a su favor, exponer los "motivos" que se tienen para sostenerlos cuando entran en conflicto con otros y son problematizados es quizás la característica fundamental del tipo de razón que para lo público deseamos. De esta forma, reflexionando en común, podemos verificar si dichos saberes merecen en realidad llamarse tales. Quizás pueda éste parecer un requerimiento excesivo sobre los sujetos que asisten al espacio público como ámbito democrático, ya que no son pocas las ocasiones en que escapan a nuestra comprensión inmediata todas y cada una de las circunstancias que en un contexto singular hicieron que nos comportáramos de una determinada manera y no de otra : nuestra particular biografía con sus experiencias, tradiciones, deseos e intereses, entre muchos otros, que no siempre están disponibles a nuestra conciencia en el momento de optar por uno entre muchos cursos de acción posibles. Sin embargo, estimamos que no es otra cosa lo que "de hecho hacemos y exigimos a los demás ya siempre" cuando nos sentimos lesionados por una acción, o también, por el contrario, cuando al ofender o dañar a alguien se nos insta a "responder" con razones "aceptables".

En el mismo orden de ideas, la racionalidad pública refiere también al ámbito de las necesidades vitales de las personas, e incluso al de muchas de las discusiones científicas y tecnológicas cuyos efectos suelen tener repercusión en nuestras vidas, y que tantas veces pretenden ser expropiadas del debate público en la idea de que se trata de saberes estrictamente de "expertos". Aquí lo público opera como un muro de contención frente a racionalidades de tipo estratégico o instrumental. La racionalidad pública, tal como nosotros la concebimos, no se dirige claro está- a una entera comprensión y manejo de los muy distintos y amplísimos saberes por parte de cada uno de los sujetos, lo que sería materialmente imposible. Pretende ella más bien mantenernos dentro de una racionalidad intersubjetiva que en una comunidad real dada nos constriñe siempre a pensar desde el lugar de cada otro. De esta forma, resolver un problema de hambrunas o de vivienda -por ejemplo- no es, al menos en el momento en que nos decidimos a seguir un específico curso de acción, sólo una cuestión de instrumentalización de políticas públi- 
cas, pues escuchadas todas y cada una de las diferentes perspectivas podría ser en realidad cualquiera que no las negara o no las tomara en cuenta. No se trata entonces de pensar las necesidades de los otros sólo en términos de "cómo y cuando" resolverlas -aspectos, desde luego, nada desdeñables-, sino fundamentalmente en términos del reconocimiento igual a todas las personas. Ser y hacernos conscientes de esto, de que todos y cada uno de nosotros como individuos y como miembros de una comunidad estamos atravesados por muy distintas lógicas, por ejemplo, las del Estado o el Mercado ; de que no son nunca sólo "otros": "burócratas y capitalistas insensibles" los responsables de hacerse cargo de la organización de nuestra vida común, sino que es una labor en la que estamos todos implicados, desde cualquier posición que ocupemos, es lo único que podrá propiciar las condiciones que la democracia con tanta urgencia requiere.

\section{Referências Bibliográficas}

BAYNES, Kenneth. The Normative Grounds of Social Criticism. Albany : State University of New York Press, 1992.

BENHABIB, Seyla, Situating the Self. Gender, Community and Postmodernism in Contemporary Ethics, Routledge, New York, 1992.

CALHOUN, Craig (Ed.). Habermas and the Public Sphere. Massachusetts: Massachusetts Institute of Technology. 1993.

COHEN, Jean L., ARATO Andrew. Civil Society and Political Theory. Massachusetts: The MIT Press, 1997.

HABERMAS, Jürgen. Conciencia moral y acción comunicativa. Barcelona: Península, 1996.

HABERMAS, Jürgen. Facticidad y validez: Sobre el derecho y el Estado democrático de derecho en términos de teoría del discurso. Madrid: Trotta, 1998.

HABERMAS, Jürgen. Historia y crítica de la opinión pública. La transformación estructural de la vida pública. Barcelona :Gustavo Gili, 1997. 
HABERMAS, Jürgen. Teoria de la acción comunicativa. Taurus: Madrid, 1999.

HELLER, Agnes. The concept of the Political revisited. In: HELD, David (Ed.) Political Theory Today. Oxford: Polity Press, 1995.

HERNÁNDEZ VEGA, Raúl. Análisis de dos discursos de la sociedad civil en Kant. México: Universidad Nacional Autónoma de México, 1991.

KANT, Immanuel. Crítica del Juicio. Madrid: Espasa Calpe, 1997.

KANT, Immanuel. Fundamentación de la Metafísica de las Costumbres: Crítica de la Razón Práctica. México: La Paz Perpetua, 1996.

KANT, Immanuel. Ideas para una historia universal en clave cosmopolita y otros escritos sobre Filosofía de la Historia. Madrid: Tecnos, 1994.

KANT. Immanuel. La Metafísica de las Costumbres. Madrid: Tecnos, 1994.

McCARTHY, Thomas. Constructivismo y reconstructivismo kantianos: Rawls y Habermas en diálogo. In: GIMBERNAT, José A. (Ed.). La filosofia moral y política de Jürgen Habermas. Madrid: Biblioteca Nueva, 1997.

RAWLS, John. Collected Papers. Cambridge: Harvard University Press, 1999.

RAWLS, John. El liberalismo político. Barcelona: Crítica, 1996.

RAWLS, John. Teoría de la Justicia. Madrid: Fondo de Cultura Económica, 1995.

RAWLS, John ; HABERMAS, Jürgen. Debate sobre el liberalismo político. Barcelona: Universidad Autónoma de Barcelona, 1998.

THIEBAUT, Carlos. Vindicación del ciudadano: Un sujeto reflexivo en una sociedad compleja. Barcelona: Paidós, 1998.

WELLMER, Albrecht. Ética y diálogo: Elementos del juicio moral en Kant y en la ética del discurso. Barcelona: Anthropos-Universidad Autónoma Metropolitana, 1994. 


\section{Abstracts}

The present article is an effort to demonstrate that a consistent discourse about democracy and human rights has to consider the existence of public spaces that ensure the plurality of positions and actors. But a public space does not mean solely the space for conflict, which shelters all those who are involved and guarantees their right to speak; neither does it mean a community harmoniously founded in tradition or religion, but rather a space based on which it is possible to welcome and legitimate different positions in an ethic way, evidently without constraints.

Key-words: public space; public participation; citizenship.

\section{Resumo}

O artigo é um esforço de reflexão para demonstrar que um discurso consistente a respeito da democracia e dos direitos humanos tem que levar em conta a existência de espaços públicos que assegurem a pluralidade de posições e atores. Mas esse público não significa, apenas, espaço de conflito que abriga todos os envolvidos e lhes assegura a fala, também não significa uma comunidade harmoniosamente fundada na tradição ou religião, mas um espaço voltado à construção de um mundo comum e, nestes termos, um espaço a partir do qual se possa eticamente e, evidentemente, sem constrangimentos, acolher e legitimar as mais distintas posições.

Palavras-chave: espaço público; participação política; cidadania. 